\title{
APPLIED SEDIMENTOLOGY: AN APPROACH TO THE EXPLORATION AND EXPLOITATION OF PETROLEUM RESOURCES
}

by

Paul B. Basan and Doris M. Curtis

\begin{abstract}
This paper examines traditional as well as new concepts in sedimentology and their special application in petroleum geology. Discussion focusses on the sedimentologic concepts used to interpret depositional environments, vertical and lateral sequences, and the diagenetic factors that must be considered in finding and producing oil and gas. It demonstrates how basic sedimentologic information can be used to formulate concepts where little or no "hard" data are available. Within the framework of these sedimentologic concepts, the future needs of the science to solve critical problems facing the petroleum industry are also considered. The topic is particularly timely for IUGS in view of the Executive Committee's recent decision to establish an ad hoc Committee on Sedimentology* which will study possible ways in which international cooperation among the world's sedimentologists, especially in the applied and interdisciplinary areas, could be increased and improved.
\end{abstract}

\section{Introduction}

Sedimentological principles have always been used by the petroleum industry, but in recent years the need to apply well-conceived and highly refined environmental models in the search for hydrocarbons has increased. Only some of the developments of applied sedimentology are addressed here. Rather than attempting to present a detailed or restricted dissertation on sedimentology in petroleum geology, this paper is meant to give a general overview to a broad range of geoscientists in many disciplines.

The field of sedimentology has developed rapidly during the past 50 years, but especially since the mid-twentieth century. In North America, Twenhofel's Treatise on Sedimentation was a principal summary of the "state of the art" before World War II. Although it dealt extensively with all aspects of sedimentary agents, processes and products, as well as with depositional environments, the work was largely descriptive.

In the 1930's, sedimentologists devoted much of their research effort to analyzing and describing the structural, textural, and mineralogical characteristics of sediments and sedimentary rocks. Relatively little work on carbonate sedimentology was done at that time. Research focussed on measuring the sizes and shapes of detrital grains in' a set of samples, plotting the distribution of these parameters, and separating and identifying the so-called "heavy" minerals. Information extracted from such studies was used to relate the products of sedimentation (that is, the sediments and the rocks) to geological processes, depositional environments, and the geological history from which these products resulted.

After World War II, several noteworthy developments dramatically affected the course of sedimentology in North America. One of these was the publication of Stratigraphy and Sedimentation by Krumbein and Sloss, which placed increased emphasis on quantitative analysis of sediments and, even more significantly, established the concepts of interpreting geological history and depositional environments from sedimentary sequences as parts of depositional systems. Another noteworthy development was the beginning of intensive and systematic study of modern sedimentary processes and products and their resulting depositional sequences and systems.

Recognizing the importance of this type of research in petroleum exploration, the American Petroleum Institute funded a massive interdisciplinary investigation in the Gulf of
Mexico. A large number of scientists from a consortium of universities and oil companies cooperated in it, studying sedimentary processes and products in surface sediments and near-surface cores. This research effort was the beginning of numerous studies of deltaic, coastal, and continental shelf sedimentation and resulted in concepts that could be directly applied to exploration.

Concurrently, carbonate sedimentologists began the stillcontinuing studies of modern reef tracts and associated deposits, and of the processes that resulted in these types of sedimentation. Research on Recent carbonates produced the first systematic, consistent approach to classifying carbonate sediments and to interpreting the genetic significance of carbonate rock textures. Application of these concepts to the study of carbonate rocks in outcrops and cores led to the recognition of the great importance of diagenetic effects, a factor whose importance in rocks of detrital origin has only recently come to be fully understood.

The analysis of depositional environments is critical in predicting unexplored objectives as well as in the efficient development of known exploration objectives. In order to use depositional models effectively, a great deal of research was necessary to refine concepts of depositional systems. Many of the refinements to the definition of environmental models have come from process-response sedimentological concepts. Studies such as those by Shinn and Ginsburg on carbonate

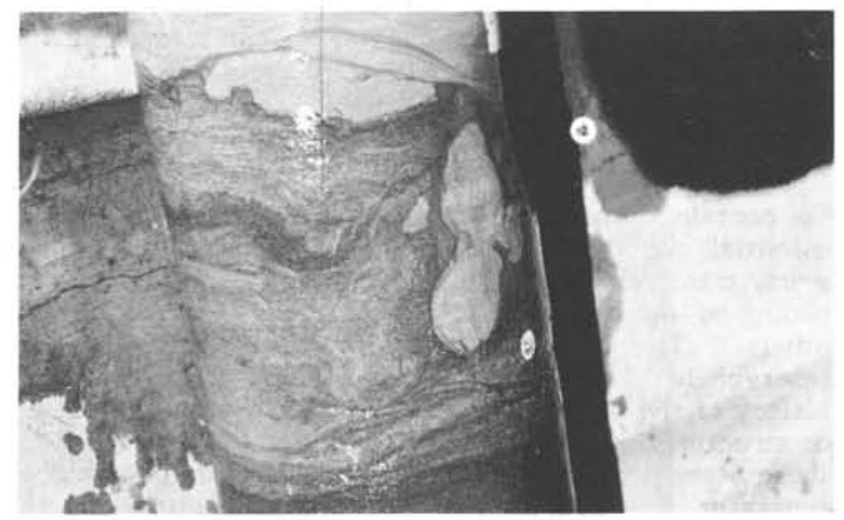

Slump structures in drill core indicating environmental origin of sediments.

*Initial members of the ad hoc committee are K.J. Hsu (Switzerland), representing the IAS, P.P. Timofeev (U.S.S.R.), Chu-Hsiu (P.R.C.), W.S. Al-Hashimi (Iraq), Keith A.W. Crook (Australia), Doris M. Curtis (U.S.A.), representing SEPM.

EPISODES, Vol. 1981, No. 1. 
Sediments under which the source bed is buried contain the sequence through which the hydrocarbons migrate after being expelled from the source bed, and also the sequence which may include the reservoir rock and the seal.

The tectonic setting of the basin during basin filling, the climate, and the depositional environment all determine the nature of the sedimentary sequence that contains the migration paths, reservoirs, and seals. A few examples of sedimentary sequences in some tectonic settings might include: (1) a regressive detrital deltaic sequence deposited during progradation and filling of an Atlantic-type passive margin; (2) a similar regressive basin-filling sequence of a foredeep; (3) a thick carbonate sequence deposited on a stable platform, with a reef build-up at the shelf margin; (4) a volcaniclastic sequence deposited in a fore-arc or back-arc basin; (5) a thick deep-water clastic sequence in a basin related to strike-slip and transform faulting.

Sedimentary sequences in the first two examples (regressive basin-fill) contain countless series of major and minor cycles of coarsening-upward regressive sandy sequences, separated by major and minor transgressive shaly sequences. The resulting monotonous series of alternating sandstones and shales may provide multiple reservoirs and seals. The reservoirs are principally in the regressive sands below the transgressive shales that form the seals.

Sedimentological applications are found at many levels of exploration in such settings. The initial application is to identify the tectonic setting and thus predict the expected type of sedimentary sequence. The Tertiary of the U.S. Gulf Coast is a classic example of a regressive basin-fill on a subsiding passive margin. The dominant type of basin-fill is deltaic, but the depositional systems contain related strandplain and interdeltaic deposits. The major "mega-cycles" or sequences can be identified from seismic records in unexplored basins, and once subsurface exploration begins, it is possible from limited subsurface control to locate a depocenter for each major cycle. The depocenters are sites of thick fluvio-deltaic and deltaic deposition, and these systems tend to develop in a direction perpendicular to a shoreline direction for a given cycle.

Associated with each deltaic system (and in a different locus for each major cycle) are the inter-deltaic and extra-deltaic environments, including bays, strand plains, and barrier bars, oriented parallel to the regional depositional strike. Although individual sediment-body geometries and individual sedimentary structures seldom are diagnostic, sets and/or sequences of these features can be used to identify certain depositional environments in outcrops and cores. With experience, wireline log character (such as gamma ray or spontaneous potential) calibrated to cores can also be used to interpret depositional environments.

Sand distribution maps, on either a gross regional scale or a detailed local scale, may show patterns that indicate reservoir geometry. It is obvious that in exploring downdip in each cycle, one would seek extensions of sands (reservoirs) in front of deltaic depocenters, whereas in interdeltaic areas exploration should proceed along the depositional strike within each cycle.

Sedimentologists have also made a distinction between "destructive" types of deltas that are wave or tide dominated with limited seaward extent, and "constructive" types that are river dominated and may have considerable seaward extent. Within the past decade sedimentologists have also established criteria for recognizing submarine fan systems, which may contain reservoir beds and seals in a dominantly marine setting.

In exploring and developing carbonate reservoirs, the identification of facies from depositional settings such as platform, lagoonal, back reef, reef, and fore reef requires the use of many geological analyses including petrology and paleontology, as well as sedimentology. Understanding the entire depositional system permits recognition of source, reservoir, and sealing facies. Extensive carbonate deposits commonly develop in stable intracratonic basins and on passive margins where the influx of terrigenous material is low. The thickness of carbonate sequences varies with the tectonic setting (which determines rates of subsidence), climatic conditions, and tectonic events in neighboring regions.

An example of a carbonate depositional system that existed for a long period of geological time and developed great thicknesses of carbonate rock sequences is found in the Neocomian-Aptian-Albian rocks of the U.S. Gulf Coast. There, a series of reefs of several ages was developed at the edge of a carbonate platform. Each reef buildup and reef front contains potential reservoir beds, and the source and sealing elements are found in associated parts of each depositional system. Although reefs are now identifiable from reflection seismic records, early exploration for these reefs was assisted by the recognition of a predictable sequence of facies that were identified in cores.

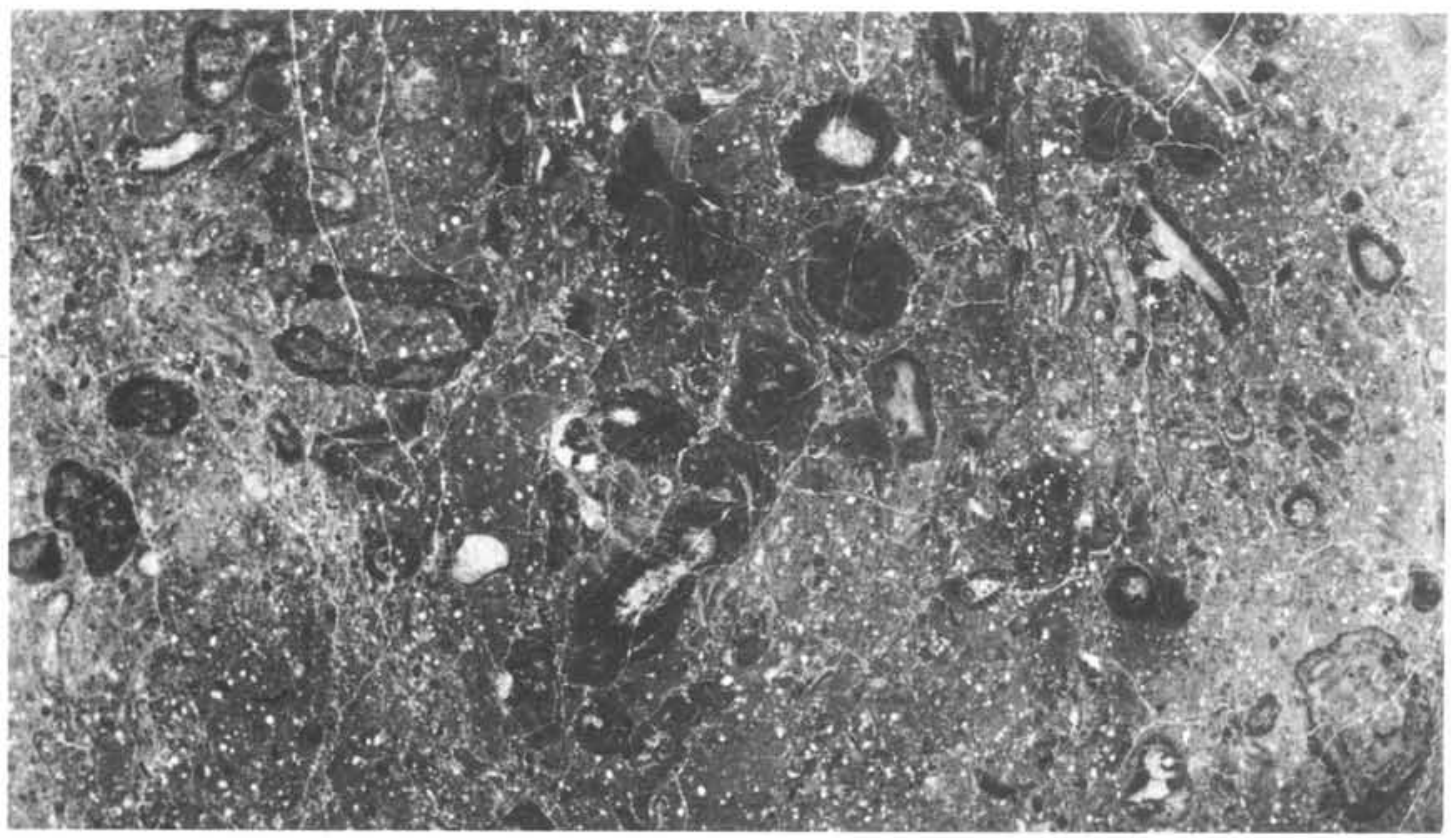

Figure A. Polished core of nonporous limestone ("oncolite floatstone") consisting of oncolites dispersed in a skeletal and micritic (mudstone) matrix. The rock lacks both primary and secondary porosity except for traces of porosity in.very fine fractures. Arrow indicates top of core; magnification: 1.5 . 


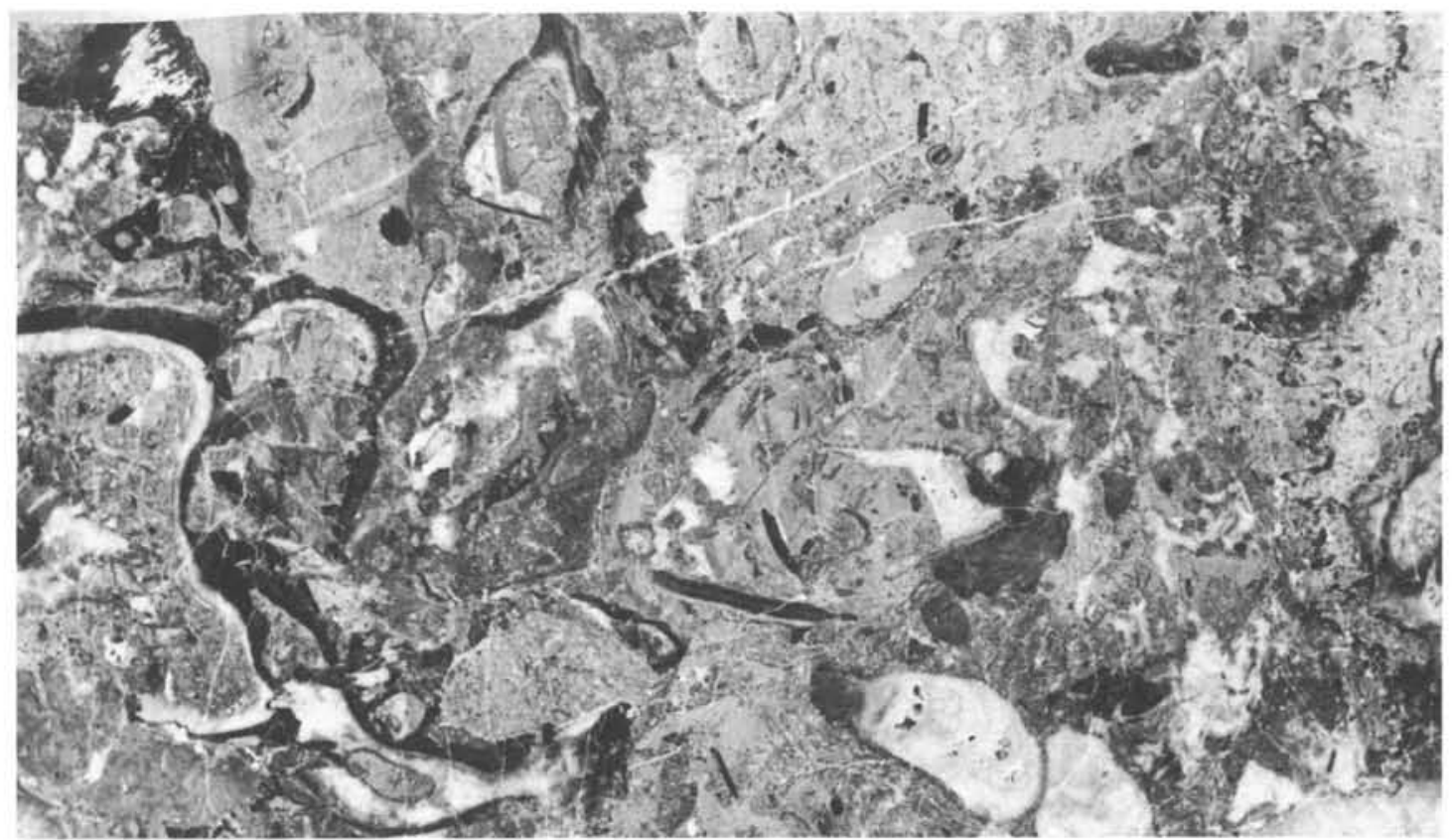

Figure B. Polished core of porous limestone ("rudist-coral-floatstone") consisting of rudists, corals, and shell fragments dispersed in a skeletal and micritic (mudstone) matrix. Cavities within the fossils are partly filled with cement, exhibiting both primary voids and secondary (leached) voids. Arrow indicates top of core; magnification: 1.5 .

An ideal transgressive reef sequence grades vertically upward from a thinly laminated, fine-grained, low-energy restricted lagoonal facies (possible source bed) through well-bedded, fossiliferous back-reef facies (Fig. B) overlain by a massive, coarse-grained shelly reef facies (possible reservoir beds). This is, in turn, overlain by a coarse-grained, high-energy, thick-bedded fore-reef facies (also possible reservoir beds). At the top of the sequence, there is a fine-grained, fossiliferous, well-bedded open-marine facies (Fig. A) which forms a possible seal. The vertical lithologic sequence for a regressive reef sequence is, of course, the reverse. These data, along with an appreciation of Johannes Walther's observation that the vertical sequence duplicates the lateral sequence, allows one to predict whether to drill seaward, landward, or downward in order to find the carbonate reservoir.

\section{Trapping Mechanisms}

The factors that cause oil and gas to be trapped are many and varied. Trapping may result from structural or stratigraphic (sedimentological) factors, or both. Indeed, sedimentological factors may have a strong influence on the size, shape, or volume of a structurally controlled accumulation, and many of us have learned that most traps have at least some sedimentological control. Sedimentological controls of accumulation are all related to pore-size variations, whether these result from an original depositional condition or a postdepositional diagenetic effect. Factors that affect trapping include such depositional features as sand "pinchouts" and facies changes, or diagenetic effects such as clay growth and/or cementation. As in all other aspects of petroleum exploration, a sophisticated working model that includes all of the factors in a trapping mechanism improves the chances for success in an exploration venture.

\section{Sample Interpretation}

As mentioned above, rock material may not be available for regional evaluations in some cases. Lack of samples or relevant data such as cores or cuttings, and sometimes even wireline logs and geophysics, is especially pronounced in offshore areas and inaccessible frontier areas. However, where available, rock samples can provide data for useful geological deductions to enhance an exploration prospect (play), add credence to a prospect or identify a new one.

The "art" of core and ditch sample description is acquired EPISODES, Vol. 1981, No. 1. after overcoming a common geological disease - "borehole myopia" - which forces even the best geologists to limit their interpretation to the well for which samples are available, and diminishes their ability to extrapolate beyond the borehole. The cure for borehole myopia is a solid background in geology, especially sedimentology, an active imagination that allows three-dimensional visualization, and a very liberal dose of "Walther's Law".

Basically the idea is to use sedimentological and/or paleontological information to reconstruct the vertical facies package(s) represented by the samples, interpret the depositional environment(s) shown by the facies package, and decide which depositional model best fits the interpretation. Once the depositional model is set, it is possible to project facies packages away from the borehole to get a broader view of the depositional system. With practice and confidence many kinds of interpretations can be made - indeed sometimes they must be made - from a single core or set of cuttings. Nevertheless, sample information over a desirable stratigraphic interval and geographically positioned to cover strategic areas is recommended whenever feasible.

Depositional models are used as the framework, albeit flexible framework, to permit the addition of new information or even to permit the entire model to be changed because of more enlightening information. With a depositional framework in mind, the geologist can make all or some of the following projections: 1) possible types of reservoir bodies present in the region (for example, distributary mouth-bar, reef); 2) possible distribution of reservoir bodies based on the geographical relationships between nonreservoir and reservoir bodies (such as the location of barrier islands in relation to the back-barrier areas); 3) some preliminary estimates of reservoir geometries; 4) regional trends of potential reservoir bodies in relation to depositional dip and regional structural elements; 5) trends in porosity development and the relationship between porosity and depositional trends.

With more sophisticated studies, the depositional model can accommodate other observations that are important not only for exploration but also for post-exploration operations, such as distribution of diagenetic products, areas where porosity is preserved or where secondary porosity has developed, and even lithologies where fractures are more likely to occur. 


\section{Sedimentology in Petroleum Exploitation}

The outcome of regional evaluation leads to the first phase of a continuing process, exploration, which is followed by exploitation and development. Sedimentology, however, as an ever-developing science, or as applied concepts, does not end at the exploration phase. We know today that sedimentological properties can be used to help design systems for the drilling of wells and well completion, as well as ultimate exploitation of hydrocarbon reservoirs.

Almost every discipline of geology can be used during the exploration phase, and many during exploitation and development. Any attempt to categorize various analyses or thought processes into exploration or post-exploration geology is therefore artificial. Nevertheless, certain aspects of sedimentology, or "soft-rock" geology as a whole, gain prominence in the phase that begins with drilling and ends when the reservoir is completely drained; many aspects of sedimentology impinge on fields such as mud engineering, reservoir and production engineering, drilling, well completion and even production geophysics, because the reservoir is a finite sediment body that is part of a stratigraphic interval.

Everything that happens to a reservoir after the bit penetrates into the sediment body has an effect on the potential of that reservoir to yield hydrocarbons, on the rate at which it will yield hydrocarbons and, too of ten, on how much and/or how long the reservoir will produce. Sedimentology, and closely allied geological disciplines such as mineralogy, geochemistry, and sedimentary petrology are critical in this post-exploration phase.

\section{Diagenetic Effects}

The prime geological culprit for creating a variety of wellbore problems is diagenesis, a process that includes many of the changes that take place in a sediment after deposition. A reservoir does not usually have the same characteristics it had at the time of deposition. Thus, a reservoir is a composite of its depositional properties and its diagenetic properties. The mere process of lithification changes many of the desirable properties of hydrocarbon reservoirs by decreasing permeability and porosity. Often the mineral composition of the sediment body at the time of deposition is changed drastically as a result of pore-fluid chemistry, which can change through time. As a result, sediment bodies that were virtually clay free at the time of deposition may now contain a variety of authigenic clay minerals.

As pessimists, therefore, we can view diagenesis as a detrimental process because generally it occludes pore spaces and deposits authigenic minerals around and within pores. Some of these minerals are sensitive to many kinds of introduced fluids. The rock-fluid interactions from ionic exchange between the "native state" reservoir and the introduced fluids or materials often determine the ultimate productivity of a well.

Optimists note that diagenesis can turn a previously nonreservoir rock into a reservoir, as in the case of leaching or dolomitization. Certain kinds of clay minerals, such as chlorite, also tend to inhibit the growth of quartz cement, and thus can cause preservation of porosity. One concludes, therefore, that diagenesis is a mixed blessing.

\section{Drilling}

The most reliable exploration tool is the drill because only a borehole into a reservoir will confirm the presence of hydrocarbons. The drill should be the explorationist's "friend" but, like all friends, when misused it can become a powerful enemy. An improperly drilled well can either reduce the productivity of a well or render it nonproductive. In general, drilling-system design should not only take into account the type of hydrocarbon expected, but also anticipate various drilling problems and the mineralogy of the reservoir.

Although a good rule of thumb is to drill oil wells with oilbased muds and gas wells with water-based muds, several kinds of problems can result from an improperly designed mud-drilling system. For example, if a water-based mud that EPISODES, Vol. 1981, No. 1. has a different $\mathrm{pH}$ from the native state reservoir is used to drill into a formation containing smectite-family clay minerals, this can cause the clays to swell into the pore spaces or migrate into pore throats, thus completely eliminating communication between the formation and the wellbore.

Such damage can require costly cleanup operations that, if not carefully conceived, can further damage the wellbore. For instance, most "mud acid" used to clean up a wellbore is a "slug" of hydrochloric acid followed by a "slug" of hydrofluoric acid. $\mathrm{HCl}$ is supposed to eliminate carbonate minerals, and HF acts on the alumino-silicates. If, however, calcium carbonate remains in the formation, calcium fluoride precipitates in open pores or fractures. This particular precipitate is insoluable.

Another example is the use of ligno-sulphonate mud, which creates free sulphate ions in the system. A common additive to mud systems is calcium carbonate, which can provide free calcium ions in the system. As a result of improper planning, gypsum may precipitate in pore spaces and block communication to the wellbore. A good policy for drilling a well, therefore, is to follow some simple rules: 1) know the mineralogy of the reservoir; 2) do not cut expenses by using an improper drilling material; and 3) monitor the system for quality control.

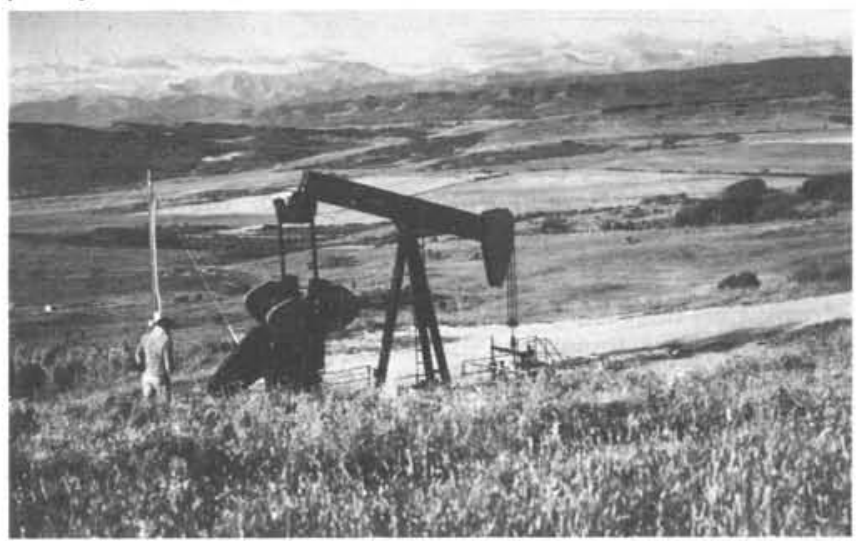

Rotary pump at work in Turner Valley, Alberta's still active, first major oil field; Canadian Rocky Mountains are in background. (Photo courtesy M. Holtz, NEB)

\section{Completion}

Well completion is a rather complex operation that can include simple cleanup of the wellbore, cementing, and well stimulation by acidizing or fracturing the reservoir. A geologist might question what these operations have to do with sedimentology. Many completion techniques, however, involve the use of chemicals that can have an adverse effect on the mineralogy, and thus an adverse effect on the reservoir.

For example, chlorite, siderite, ankerite or other iron-rich minerals can react with hydrochloric acid to form iron hydroxide precipitates, which are gelatinous globules that can migrate into pore spaces. Abrupt changes in $\mathrm{pH}$ can cause kaolinite, illite, and other clays to break free of grain attachments and migrate into pores (Fig. C). Again, proper planning and sound sedimentological information can make the difference between a productive and a nonproductive well.

\section{Enhanced Recovery}

A frustrating fact is that primary production commonly recovers no more than a third of the oil in place. Secondary methods, such as water flooding, may recover another $10 \%$. The remainder must either be recovered by tertiary or enhanced oil recovery (EOR) methods, or remain forever trapped in the reservoir. As a result, every successful wildcat drilled today should cause the initiation of a development plan by the producer, to ensure that the reservoir is damaged as little as possible. Such action could result in the field becoming amenable to one or more of the processes recovering additional oil from it. 


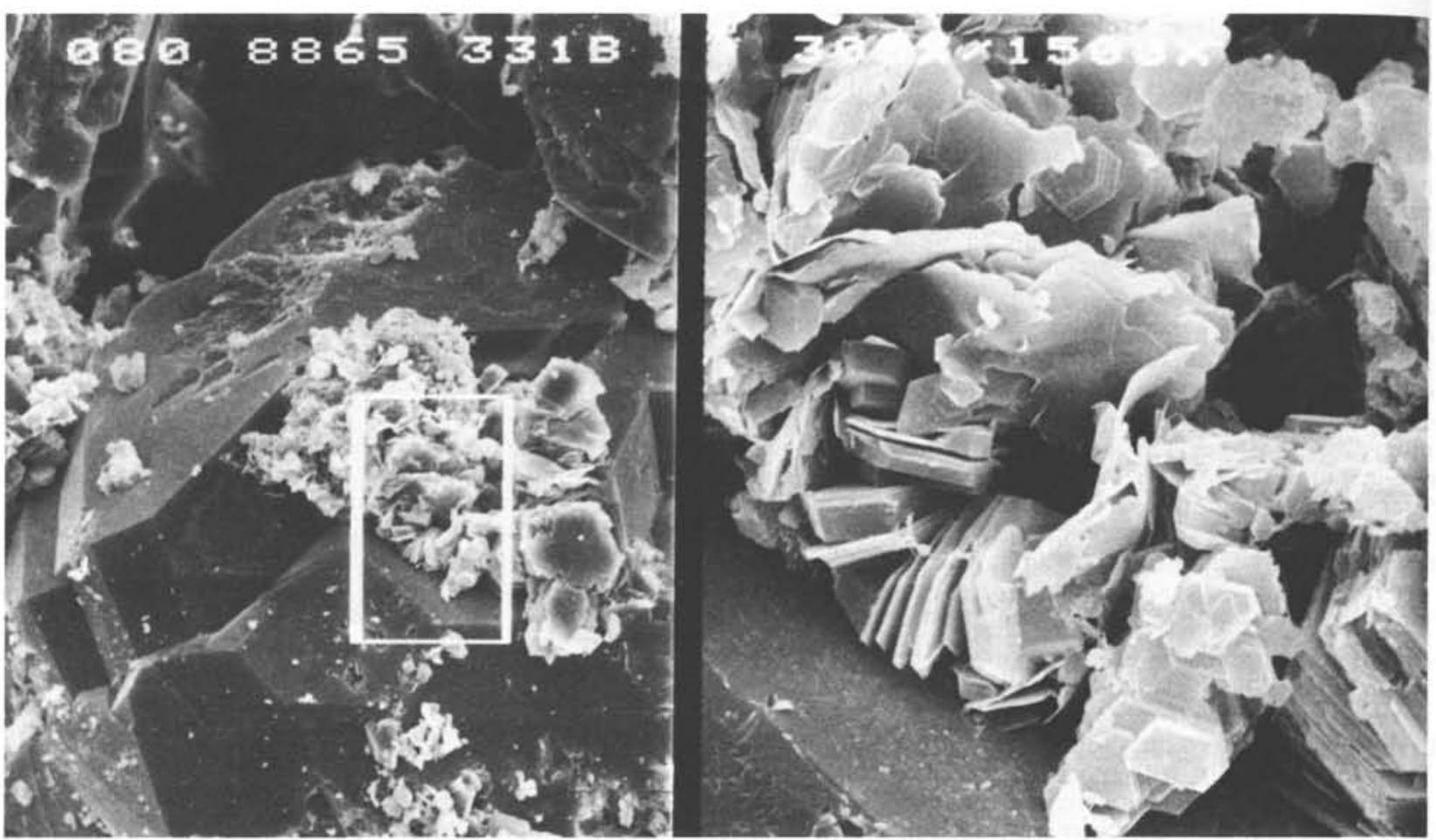

Figure C. Split-image SEM photograph showing a quartz grain coated with authigenic kaolinite. The highly magnified right side of the photograph shows the morphology of kaolinite booklets. Magnification: left - 300, right - 1500 .

Because of the cost of recovering petroleum, and the kind of information necessary for successful projects, sedimentology is perhaps more important in its use in reservoir geology than in any other aspect of the industry. A simple fact is that more detailed and accurate geology is needed to recover petroleum than to find it. Consequently, depositional models must be accurate to define the gemetry of reservoir bodies, establish continuity of permeable horizons and lead to the design of the location of injector and producer wells. Sedimentological features, such as cross-bedding, must be documented to show where possible directional permeability may occur. The mineralogy of the reservoir must be compatible with the enhanced recovery process, whether it is simply untreated water, steam, or fire, or complex polymers.

\section{The Challenge}

In addressing the subject of applied sedimentology, it is difficult to leave out the intimately allied discipline of sedimentary petrology and the important role played by mineral chemistry and clay mineralogy in exploration and exploitation of hydrocarbon reserves. Two very different kinds of events have occured over the last decade that have had a reinforcing effect on sedimentology and sedimentary petrology. One of these events was the development of instrument technology, especially the increasing use of trans-

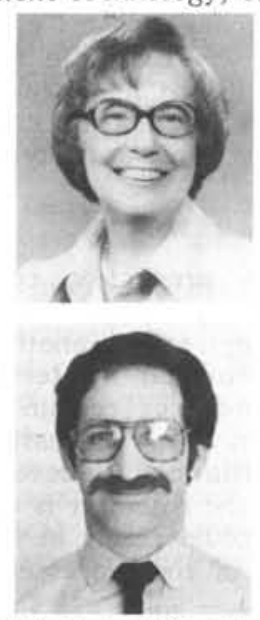

\section{ABOUT THE AUTHORS:}

mission electron microscopy (TEM), scanning electron micro scopy (SEM), and the microprobe. Closely related to electron microscopy was the development of energy-dispersive X-ray (EDS or EDAX), which allowed scientists to make elemental analysis of minerals directly from the electron microscope.

The other event was the need for industry to use such sophisticated technology. From 1973 on, oil and oil byproduct shortages created an economic climate suitable to cause exploration companies to use these instruments to evaluate reservoirs previously considered uneconomical or marginally economical.

We have only scratched the proverbial surface of both need and technology because our need for hydrocarbon products has increased the reasons for better, more efficient exploitation. Indeed the problems, present and future, are complex. Even the answers we have today are complex because they require the skills of many different types of professionals.

The challenges for the future are unique. In many ways, the days of the specialist are coming to an end. Sedimentologists must also be low-temperature geochemists, reservoir and mud engineers, as well as broadly based geologists. We must look at old ideas in new ways. We must be able to decipher the sedimentology of a province, basin or reservoir more accurately. We need new tools or new clues for interpreting cores, cuttings, wireline logs, geophysical records, and other data so that we can accomplish our task more quickly and more economically and, indeed, so that we can accomplish the task with fewer costly mistakes.

Doris M. Curtis, a member of the consulting partnership of Curtis and Echols, is Consultant Associate to Robertson Research (U.S.) Inc. in Houston, Texas, U.S.A. Formerly with Shell Oil Company, her principal interests are stratigraphic analysis, basin evaluation, and deltaic sedimentology. She is President of the American Geological Institute, a member of the U.S. National Committee on Geology, and of the IGCP Scientific Committee.

Paul B. Basan is Director of Reservoir Geology and Sedimentology at Robertson Research (U.S.) Inc. in Houston, Texas. His career began with Texaco, Inc. as a petroleum geologist and, after receiving his Ph.D., he continued with Amoco Research as a research scientist. Returning to exploration with Union Texas Petroleum, he later joined Robertson Research. Paul Basan is a member of the SEPM Research Committee and an associate editor of the Journal of Sedimentary Petrology. 